Bangladesh Journal of Medical Science Vol. 11 No. 03 July’12

Editorial

\title{
Changing pattern of Peripheral Vascular disease in Asian countries
}

Khan MI

Peripheral vascular disease (PVD) is one of the common conditions that have the potential threat to limb loss or even loss of life. Peripheral vascular disease manifests as inadequate tissue perfusion caused by atherosclerosis leading to critical narrowing of the supplying vessels. The major risk factors for PVD include smoking, hyperlipidemia, diabetes mellitus, and hyperviscosity ${ }^{1}$. Thromboangiitis obliterans (TAO) remains an enigmatic systemic vasculitis strangely linked to smoking; determining its occurrence, progression and prognosis. The precise mechanisms are still elusive. Except for discontinuation of tobacco use, there is no other definitive therapy ${ }^{2}$. Selective cannabinoid receptor antagonists have shown promise for helping patients to stop smoking. Prostacycline analogues may help patients with critical limb ischaemia. Recent innovative genetic and cell-based therapeutic approaches have been proposed to induce angiogenesis but they require evaluation in randomized controlled trials to confirm their beneficial effects in patients with $\mathrm{TAO}^{3}$.

Uncontrolled or poorly controlled hypertension is one of the major contributing factors in Asian countries in the development and progression of PVD. Other universally recognize risk factors like smoking, diabetes, obesity (a body mass index over 30), high blood pressure (140/90 millimeters of mercury or higher), high cholesterol (total blood cholesterol over 200 milligrams per deciliter, or 5.2 millimoles per liter), increasing age, especially after reaching 50 years of age, a family history of peripheral vascular disease, coronary artery disease or stroke, excess levels of homocysteine, a protein component that helps build and maintain tissue, are more frequently encountered in Asian countries ${ }^{4}$. People who smoke or have diabetes have for greatest risk of developing peripheral vascular disease due to reduced blood flow. Other causative factors for developing PVD may include phlebitis, injury or surgery, and autoimmune disease, including vasculitides, arthritis, or coagulopathy ${ }^{5}$. Acute emboli causing limb ischemia may be due to acute or chronic atrial fibrillation, valvular heart disease, or recent myocardial infarction, whereas a history of intermittent claudication, and rest pain suggests thrombosis of existing PVD ${ }^{6}$. The early symptomatic PVD might manifest in the form of intermittent claudication. The level of ing vascular occlusion is determined by the intermittent pain and it's manifestations like: aortoiliac disease presenting as pain in the thigh and buttock, whereas femoral-popliteal disease causing pain in the calf. Pain is precipitated by walking a predictable distance (Claudication distance) and is relieved by rest. In chronic disease, collateral circulation may develop; reducing the symptoms of intermittent claudication, but failure to control precipitant factors and risk factors often causes its reemergence. At times the misleading factors might exist in PVD causing intermittent pain in the hip or leg "giving out" after a certain period of exertion and may not demonstrate the typical symptom of pain on exertion. It is unusual to experience pain while sitting or standing, if the limb is not critically ischaemic ${ }^{7}$. In chronic limb ischemia, rest pain is more worrisome; it refers to pain in the extremity due to a combination of PVD and inadequate perfusion and is sign to impending limb loss if not immediately revascularised ${ }^{8}$.

PVD may lead to life threatening emergency, if the limb is not timely revascularised. To reduce the morbidity and mortality, appropriate interventions by the expert vascular surgeon are mandatory. Since last two decades rapid changes are taking place in the pattern of cardiovascular disease in Asian countries like Middle east, Iran, Pakistan, India, Singapore, Hong Kong china, Japan, Malaysia and others. A steep rise was observed in prevalence of PVD in Asian countries especially during the last two decades. ${ }^{9}$ This is reflected in the large experience of 314 patients undergoing 349 consecutive femoropopliteal bypass procedures reported in this issue from the Queen Mary Hospital, Hong Kong. Other significant reports on peripheral vascular dis- 
ease in Asia have come from the same institution. These have included an experience with 533 patients undergoing abdominal aortic aneurysm surgery between 1975 and 1995, again demonstrating a rising annual incidence of a peripheral vascular disorder in Hong Kong. ${ }^{10}$ The risk factors observed in these studies was similar to that seen in western populations, with male dominance (1.6:1), smoking (59\%), hypertension (55\%) and diabetes mellitus (42\%). Lipid abnormalities were also documented and they included hypercholesterolemia (55\%) and elevated low-density lipoprotein (60\%) and triglyceride (31\%) levels. ${ }^{3}$ Atherosclerotic occlusive disease predominantly affected the femoropopliteal segment (49\%). In a similar interval (1978-1996) only 89 confirmed cases of Buerger's disease were seen $^{11}$.

Changing trends in the Asian countries is similar as in the western countries. A multicenter cross-sectional study was carried out at eight centers in all the provinces of Pakistan on people with type2 Diabetes mellitus. The study demonstrates a high prevalence of PVD among people with type 2 diabetes in Pakistan which needs to be appropriately evaluated by the medical professionals ${ }^{12}$. Perhaps the most disturbing aspect of the changing epidemiology, with profound implications for health resource planning, is the escalating prevalence of type 2 diabetes mellitus: a level of 300 million diabetic individuals is projected worldwide by 2025, almost half of whom will be in the Asia-Pacific region. An Indian study concluded that the population of India is steadily aging and the prevalence of diabetes is rising sharply. PVD as one of the complication of diabetes will emerge as a very significant cause of morbidity and mortality in India ${ }^{13}$.

That this will result in a need for additional vascular surgical expertise and facilities seems inevitable. Among non-communicable diseases, cardio-vascular diseases (CVD) are an important public health problem. Although no accurate data is yet available, the burden of CVDs is expected to be high in view of behavioral and lifestyle changes in developing countries like Pakistan, India, china, Hong Kong and other countries. The prevalence of peripheral vascular disease (PVD) is rising in line with an ageing population. There is a strong association with concomitant coronary artery and cerebral vascular disease in these patients, which represents a significant cause of mortality and morbidity in patients with PVD $^{14}$. Disease affecting the lower extremity peripheral vessels is most aggressive in smokers and diabetics and more worse if two are more factors are contributing simultaneously ${ }^{15}$. Moreover, many primary care physicians and the majority of citizens do not possess adequate knowledge concerning the prevention and management of cardio-vascular diseases $^{16}$. We foresee the major disease burden in Asian countries in next two decades and accordingly all stakeholders must plan and adopt appropriate proactive strategies for prevention and management of peripheral vascular disease in the region ${ }^{17}$. The academic institutions must re-appropriate their human and material resources aiming to effective preventive and curative measures for PVD and we should establish more vascular units in our hospitals to get by the emerging situations.

The author is a consultant vascular surgeon and Dean/ Principal of AJK Medical College Muzaffarabad (Pakistan) 


\section{References:}

1. Kannel WB, McGee DL. Update on some epidemiologic features of intermittent claudication: the Framingham Study. J Am Geriatr Soc. 1985; 33:1318.PMid:3965550

2. Leng GC, Lee AJ, Fowkes FG, et al. Incidence, natural history and cardiovascular events in symptomatic and asymptomatic Peripheral arterial disease in the general population. Int J Epidemiol 1996;25:11721181http://dx.doi.org/10.1093/ije/25.6.1172 PMid:9027521

3. Hiatt WR, Hoag S, Hamman RF. Effect of diagnostic criteria on the prevalence of Peripheral arterial disease. The San Luis Valley diabetes study. Circulation 1995;91:1472- 1479.PMid:7867189

4. Kinare,S.G.; Kher,Y.R.; Rao,G.; Sen,P.K. "Pattern of Occlusive Peripheral Vascular Disease in India :(Clinicopathological Study of 79 Cases) Follow Angiology $1976 ; 27 \quad$ (3): 165. 5. Laohapensang K, Rerkasem K, Kattipattanapong V.Decrease in the incidence of Buerger's disease recurrence in northern Thailand.Sug Today 2005; 35(12):1060-5.http://dx.doi.org/10.1007/s00595005-3081-9PMid:16341487

6. F. Gerald R. Fowkes, Edward Housley, Rudolph A. Riemersma, Celia C. A. Macintyre, Elizabeth H. H. Cawood, Robin J. Prescott and C. Vaughan Ruckley "Smoking, Lipids, Glucose Intolerance, and Blood Pressure as Risk Factors for Peripheral Atherosclerosis Compared with Ischemic Heart Disease in the Edinburgh Artery Study" Am. J. Epidemiol 1992; 135 (4): 331-340. PMid:1550087

7. Criqui $\mathrm{MH}$, Denenberg JO, Langer RD, Fronek A "The epidemiology of peripheral arterial disease: importance of identifying the population at risk. Vascular Medicine 1997; 2(3):221-6.

8. Leng GC, Fowkes FG, Lee AJ, et al. Use of ankle brachial pressure index to predict cardiovascular events and death: a cohort study. $\mathrm{Br}$ Med J 1996; 313:1440-1444.http://dx.doi.org/10.1136/bmj. 313.7070.1440PMid:8973232PMCid:2352992

9. Criqui $\mathrm{MH}$, Langer RD, Fronek A, et al. Mortality over a period of 10 years in patients with Peripheral arterial disease. $N$ Engl J Med 1992; 326:381-386. http://dx.doi.org/10.1056/NEJM199202063260605 PMid:1729621
10. Chen SWK, Ting ACW, Lau H, Wong. J. Epidemiology of atherosclerotic peripheral arterial occlusive disease in Hong Kong. World J. Surg 1999; 23: 202-6.http://dx.doi.org/10.1007/PL00013161 PMid:9880433

11. Cheng S, Ting AC, Wong. J. Abdominal aortic aneurysm in Hong Kong: Audit from a teaching hospital (1975-95). Chin. Med. J 1998; 111: 457-9.

12. Lau H, Cheng SWK. Buerger's disease in Hong Kong: A review of 89 cases. Aust. N.Z. J. Surg. 1997; 67: $\quad$ 264-9.http://dx.doi.org/10.1111/j.14452197.1997.tb01960.x

13. Javed Akram, Aziz-ul-Hassan Aamir, Abdul Basit, Mohammad Saleem Qureshi, Tariq Mehmood, Syed Khurram Shahid, Irshad Ahmed Khoso, Muhammad Ashraf Ebrahim, Aamir Omair Prevalence of peripheral arterial disease in type 2 diabetics in Pakistan JPMA Issue Vol:61, No:7 July, 2011

14. Zaini A. Where is Malaysia in the midst of the Asian epidemic of diabetes mellitus? Diabetes Res. Clin. Pract 2000; 50 (Suppl. 2): S23-8. http://dx.doi.org/10.1016/S0168-8227(00)00175-3

15. B P Yan, T J Kiernan, Y-Y Lam, C-M Yuhttp://heartasia.bmj.com/content/1/1/51.abstract - aff-1 'Current endovascular therapy for lower extremity peripheral arterial disease: indications, outcomes and modalities' Heart Asia 2009;1:51-57 doi:10.1136/ha.2009.000976

16. Vogt MT, Cauley JA, Newman AB, Kuller LH, Hulley SB. Decreased ankle/arm blood pressure index and mortality in elderly women. JAMA 1993; 270:465-469http://dx.doi.org/10.1001/jama.1993. $\underline{03510040069031}$

17. Rhee SY, Guan H, Liu ZM, Cheng SW, Waspadji S, Palmes P, Tai TY, Suwanwalaikorn S, Kim YS; PADSEARCH Study Group "Multi-country study on the prevalence and clinical features of peripheral arterial disease in Asian type 2 diabetes patients at high risk of atherosclerosis. Diabetes Res Clin Pract 2007 Apr; 76(1):82-92. Epub 2006 Sep 6 http://dx.doi. org/10.1016/j.diabres.2006.07.029PMid:16950543

18. Rashid ARA. The cardiovascular epidemic with particular emphasis on the Muslim world. Bangladesh Journal of Medical Science 2011; 10 (2): 65-71. DOI: http://dx.doi.org/10.3329/bjms.v10i2.7800 